\title{
UPAYA PENINGKATAN KINERJA PERAWAT GAWAT DARURAT MELALUI BERBAGAI GAYA KEPEMIMPINAN DI RSUD DAERAH ISTIMEWA YOGYAKARTA
}

\author{
Deby Zulkarnain Rahadian Syah ${ }^{1 *}$, Muhamat Nofiyanto ${ }^{2}$
}

\begin{abstract}
${ }^{* 1,2}$ Lecturer In Nursing Departement Stikes Jenderal Achmad Yani Yogyakarta, JI. Brawijaya Ring Road Barat Ambarketawang Gamping Sleman Yogyakarta, 0274 4342000, email: deby.ayani14@gmail.com dan muhamatnur@gmail.com
\end{abstract}

\begin{abstract}
Background: Nurses in charge of the Emergency Room are required to have more ability than nurses serving patients in other units. Emergency Room is an initial service in a hospital. One's leadership style will greatly affect the effectiveness of a leader. The selection of the right leadership style can lead to the achievement of individual or organizational goals.

Objective: To know the various leadership style used by the head of room in improving the performance of nurses of Emergency Room RSUD in Special Region of Yogyakarta.

Method: This research includes quantitative research type, using cross sectional approach. The population of this study was the head of the treatment room. Secondary data of nurse's performance is taken from nursing care which is written in medical record file of Emergency Room of RSUD in Special Region of Yogyakarta.

Results: The performance of nurses at Emergency Room RSUD A in the good category was $100 \%$. The performance of nurses at Emergency Room RSUD B in the enough category was $45 \%$. The performance of nurses at Emergency Room C in good category was $80 \%$. The performance of nurses at Emergency Room RSUD D in good category was $55 \%$. The performance of nurses at RSUD E in the good category was $95 \%$. The result of cross tabulation between leadership style and nurse performance of RSUD in the whole DIY with good performance is leader who use democratic leadership style equal to $35 \%$.

Conclusion: Most of the nurse's good performance in Emergency Room is followed by democratic leadership style of head of space.
\end{abstract}

Keyword: Leadership style, head of space, performance of nurses

\section{PENDAHULUAN}

Manajemen keperawatan adalah suatu tugas khusus yang harus dilaksanakan oleh pengelola keperawatan untuk merencanakan, mengorganisasi, mengarahkan, serta mengawasi sumbersumber yang ada, baik sumber daya manusia, alat, maupun dana, sehingga dapat memberikan pelayanan keperawatan yang efektif baik kepada pasien, keluarga, dan masyarakat. Sebagai seorang manajer keperawatan harus memiliki jiwa kepemimpinan untuk mencapai tujuan organisasi yang telah ditentukan melalui orang lain. Keterampilan kepemimpinan dimiliki, sehingga efektif dalam mengelola pelayanan dan asuhan keperawatan sesuai dengan perkembangan ilmu pengetahuan dan dapat memenuhi kebutuhan masyarakat. $^{1}$

Pelaksanaan kerja antara pemimpin dan karyawan dalam suatu organisasi sangat menentukan keberhasilan untuk mencapai tujuan. Seorang perawat dalam sebuah rumah sakit harus bisa mengelola pasien yang menjadi tanggung jawabnya. Dalam 
pemberian asuhan keperawatan perawat diatur dan dipimpin oleh kepala ruangan. Kepala ruangan tersebut akan menjalankan peran sebagai seorang manajer sekaligus menjalankan peran sebagai seorang pemimpin, mengatur dan mengarahkan para perawat dalam bertugas. $^{2}$

Nursalam mengatakan, dengan model kepemimpinan yang optimal tentunya akan berpengaruh terhadap output yang dihasilkan rumah sakit. Proses yang dihasilkan dalam bentuk jasa dari rumah sakit untuk mencapai visi misi yang diharapkan, merupakan salah satu peran tenaga perawat. Maka dari itu perawat dituntut harus bisa bertindak profesional. Termasuk di Instalasi Gawat Darurat (IGD) di RSUD Daerah Istimewa Yogyakarta, tenaga perawat yang sudah ada perlu ada komitmen dengan pemimpin ruangan. ${ }^{1}$

Perawat yang bertugas di IGD dituntut untuk memiliki kemampuan lebih dibandingkan dengan perawat yang melayani pasien di unit lain, karena IGD merupakan sebuah pelayanan awal pada rumah sakit. ${ }^{3}$ Pasien yang datang ke IGD tentunya mengharapkan pelayanan yang cepat dan tepat, oleh karena itu IGD memerlukan standar dalam memberikan pelayanan. Standar pelayanan IGD yaitu memiliki pelayanan 24 jam dalam sehari dan tujuh hari dalam seminggu. Untuk standar waktu response time yaitu tidak lebih dari lima menit. ${ }^{4}$
Hasil penelitian yang dilakukan Nurmawilis, menyebutkan ada pengaruh antara gaya kepemimpinan terhadap kinerja karyawan di RSUD Rokan Hulu. ${ }^{5}$ Gaya kepemimpinan seseorang akan sangat berpengaruh terhadap efektivitas seorang pemimpin. Pemilihan gaya kepemimpinan yang benar dapat mengarahkan pencapaian tujuan perseorangan atau organisasi. ${ }^{6}$

Rumusan masalah dalam penelitian ini adalah gaya kepemimpinan apakah yang digunakan kepala ruangan IGD dalam upaya meningkatkan kinerja perawat di RSUD Daerah Istimewa Yogyakarta. Tujuan penelitian ini yaitu mengidentifikasi gaya kepemimpinan yang digunakan dalam meningkatkan kinerja perawat di IGD. Luaran yang diharapkan yaitu kepala ruangan dapat mengaplikasikan model gaya kepemimpinan yang dapat meningkatkan kinerja perawat. Kontribusi bagi ilmu pengetahuan, hasil penelitian ini dapat menambah referensi gaya kepemimpinan yang cocok diterapkan kepala ruangan IGD dalam upaya meningkatkan kinerja perawat.

\section{BAHAN DAN CARA PENELITIAN}

Penelitian ini merupakan penelitian kuantitatif dengan pendekatan cross sectional. Data yang digunakan merupakan data primer yang diambil dengan cara membagikan kuesioner kepada kepala ruang keperawatan gawat darurat, untuk mengetahui gaya kepemimpinan yang dipakai. Data primer lainnya yaitu kinerja 
perawat yang diambil dari berkas rekam medis pasien untuk menilai kinerja perawat sesuai ketentuan Depkes tahun 2004 terkait asuhan keperawatan. Tempat penelitian ini yaitu di lima Rumah Sakit Umum Daerah di Daerah Istimewa Yogyakarta yaitu RSUD di Kota Yogyakarta, RSUD di Kabupaten Sleman, RSUD di Kabupaten Bantul, RSUD di Kabupaten Kulon Progo, dan RSUD di
Kabupaten Gunungkidul. ${ }^{7}$ Data univariat dari hasil akan diolah untuk mendapatkan hasil deskriptif dengan menggunakan persentase dan dibuat data tabulasi silang untuk melihat gaya kepemimpinan yang meningkatkan kinerja perawat di IGD.

HASIL DAN PEMBAHASAN

\begin{tabular}{ccc}
\hline \multirow{2}{*}{ Karakteristik } & \multicolumn{2}{c}{ Tabel 1 Karakteristik Responden $\mathbf{n = 5}$} \\
\hline Umur & RSUD DI DIY & Keterangan \\
\cline { 2 - 3 } & RSUD A & 38 tahun \\
\cline { 2 - 3 } & RSUD B & 29 tahun \\
\cline { 2 - 3 } & RSUD C & 47 tahun \\
\cline { 2 - 3 } Masa Kerja & RSUD D & 47 tahun \\
\cline { 2 - 3 } & RSUD E & 46 tahun \\
\cline { 2 - 3 } & RSUD A & 20 tahun \\
\cline { 2 - 3 } Pendidikan & RSUD B & 7 tahun \\
\cline { 2 - 3 } & RSUD C & 27 tahun \\
\cline { 2 - 3 } & RSUD D & 21 tahun \\
\cline { 2 - 3 } & RSUD E & 26 tahun \\
\cline { 2 - 3 } & RSUD A & D4 Keperawatan \\
\cline { 2 - 3 } & RSUD B & Ners \\
\hline & RSUD C & D4 Keperawatan \\
\hline & RSUD D & RSUD E \\
\hline
\end{tabular}

Tabel 1 memperlihatkan karakteristik responden dari umur paling tinggi 47 tahun dari RSUD $C$ dan $D$, sedangkan umur paling rendah 29 tahun dari RSUD B. Data masa kerja tertinggi mencapai 27 tahun dari RSUD C, sedangkan masa kerja paling rendah 7 tahun dari RSUD B.

Tabel 2 menggambarkan kinerja perawat IGD RSUD A di Yogyakarta. Hasil tabel 2 jumlah 100\% perawat IGD memiliki kinerja perawatan dalam kategori baik.
Tabel 2 Kinerja Perawat di IGD RSUD A di Yogyakarta

\begin{tabular}{cccc}
\hline Kinerja & $\mathrm{F}$ & $\%$ & Cumulative \\
\hline Baik & 20 & 100 & 100 \\
\hline & & & \\
\hline Total & 20 & 100 & \\
\hline
\end{tabular}

Sumber: Data Primer 2017

Tabel 3 menggambarkan kinerja perawat IGD RSUD B di Yogyakarta. Hasil tabel 3 sebagian besar $45 \%$ perawat IGD memiliki kinerja perawatan dalam kategori cukup. 
Tabel 3 Kinerja Perawat di IGD RSUD B di Yogyakarta

\begin{tabular}{|c|c|c|c|}
\hline Kinerja & $\mathrm{F}$ & $\%$ & $\begin{array}{l}\text { Cumulative } \\
\text { Percent }\end{array}$ \\
\hline Baik & 8 & 40 & 40 \\
\hline Cukup & 9 & 45 & 85 \\
\hline Kurang & 3 & 15 & 100 \\
\hline Total & 20 & 100 & \\
\hline \multicolumn{4}{|c|}{ Sumber: Data Primer 2017} \\
\hline \multicolumn{4}{|c|}{$\begin{array}{c}\text { Tabel } 4 \text { Kinerja Perawat di IGD RSUD C } \\
\text { di Yogyakarta }\end{array}$} \\
\hline Kinerja & $\mathrm{F}$ & $\%$ & $\begin{array}{l}\text { Cumulative } \\
\text { Percent }\end{array}$ \\
\hline Baik & 16 & 80 & 80 \\
\hline Cukup & 2 & 10 & 90 \\
\hline Kurang & 2 & 10 & 100 \\
\hline Total & 20 & 100 & \\
\hline
\end{tabular}

Sumber: Data Primer 2017

Tabel 4 menggambarkan kinerja perawat IGD RSUD C di Yogyakarta. Hasil tabel 4 sebagian besar $80 \%$ perawat IGD memiliki kinerja perawatan dalam kategori baik.

\begin{tabular}{|c|c|c|c|}
\hline Kinerja & $F$ & $\%$ & $\begin{array}{c}\text { Cumulative } \\
\text { Percent }\end{array}$ \\
\hline Baik & 11 & 55 & 55 \\
\hline Cukup & 6 & 30 & 85 \\
\hline Kurang & 3 & 15 & 100 \\
\hline Total & 20 & 100 & \\
\hline
\end{tabular}

Sumber: Data Primer 2017

Tabel 5 menggambarkan kinerja perawat IGD RSUD D di Yogyakarta. Hasil tabel 5 sebagian besar $55 \%$ perawat IGD memiliki kinerja perawatan dalam kategori baik.

Tabel 6 menggambarkan kinerja perawat IGD RSUD E di Yogyakarta. Hasil tabel 6 sebagian besar 95\% perawat IGD memiliki kinerja perawatan dalam kategori baik.

\begin{tabular}{|c|c|c|c|}
\hline Kinerja & $F$ & $\%$ & $\begin{array}{c}\text { Cumulative } \\
\text { Percent }\end{array}$ \\
\hline Baik & 19 & 95 & 95 \\
\hline Cukup & 1 & 5 & 100 \\
\hline Total & 20 & 100 & \\
\hline
\end{tabular}

Sumber: Data Primer 2017

Dari tabel 7 menggambarkan tabulasi silang antara gaya kepemimpinan kepala ruang dengan kinerja perawat IGD dengan kategori baik diikuti dengan gaya kepemimpinan demokratis.

Tabel 7 Tabulasi Silang Gaya Kepemimpinan Karu dengan Kinerja perawat

\begin{tabular}{clcccc}
\hline & & \multicolumn{3}{c}{ Kinerja } & Total \\
\cline { 2 - 5 } & & Baik & Cukup & Kurang & \\
\hline \multirow{3}{*}{ Gaya } & Konsultatif & 19 & 15 & 6 & 40 \\
\cline { 2 - 5 } & Delegatif & 20 & 0 & 0 & 20 \\
\cline { 2 - 5 } & Demokratis & 35 & 3 & 2 & 40 \\
\hline & Total & 74 & 18 & 8 & 100 \\
\hline
\end{tabular}

Sumber: Data Primer 2017

Tabel 1 memperlihatkan karakteristik responden dari umur, dengan rentang paling rendah yaitu 29 tahun dan paling tinggi 47 tahun. Usia rentang 29-47 tahun masuk dalam kategori dewasa yang dibagi menjadi 3 yaitu dewasa awal rentang 19-40 tahun, dewasa menengah 41-65 tahun, dan dewasa akhir lebih dari 65 tahun (Erikson dalam Upton). ${ }^{8}$ Adapun seseorang yang sudah dewasa memiliki ciri-ciri menurut Anderson (dalam Mubin dan Cahyadi) adalah berorientasi pada tugas, mempunyai tujuan yang jelas, dan kebiasaan kerja yang efisien, 
dapat mengendalikan perasaan pribadinya, mempunyai sifat yang objektif, menerima kritik dan saran, bertanggung jawab, dapat menyesuaikan dengan keadan yang realistis. ${ }^{9}$

Usia 29 tahun merupakan kategori dewasa awal yang secara fisik berada dalam keadaan baik serta kekuatan tenaga dan motorik mencapai masa puncak. Potter and Perry orang dewasa awal biasanya sangat aktif, jarang mengalami penyakit parah, cenderung mengabaikan gejala fisik, dan sering menunda pencarian pelayanan. Usia dewasa awal juga menunjukkan kemampuan berpikir kritis yang terus meningkat termasuk mulai persepsi diri dan kemampuan untuk akrab dengan orang lain. ${ }^{10}$

Usia dewasa menengah tampak perubahan fisik seperti rambut mulai memutih, kulit keriput dan pinggang menebal. ${ }^{10}$ Menurut Pieter dan Lubis seseorang dengan usia dewasa menengah mengalami kecemasan pada penampilan fisiknya. ${ }^{11}$

Data masa kerja tertinggi mencapai 27 tahun dan terpendek 7 tahun. Waktu kerja seseorang menentukan kesehatan yang bersangkutan, efisiensi, efektivitas, dan produktivitas kerja. Aspek penting dalam hal waktu kerja meliputi lamanya seseorang mampu bekerja dengan baik, hubungan waktu kerja dengan istirahat, dan waktu kerja sehari menurut periode waktu yang meliputi pagi, siang, sore, dan malam. ${ }^{12}$
Masa kerja adalah lamanya seorang karyawan menyumbangkan tenaganya untuk perusahaan tertentu dan menghasilkan penyerapan dari bebagai aktivitas manusia, serta mampu menumbuhkan keterampilan yang muncul secara otomatis dalam tindakan yang dilakukan oleh karyawan dalam menyelesaikan pekerjaannya. Semakin berpengalaman seorang karyawan maka akan semakin membantu perusahaan untuk menghasilkan kinerja atau output yang lebih banyak. ${ }^{13}$

Pengalaman kerja adalah proses pembentukan pengetahuan atau keterampilan tentang metode suatu pekerjaan karena keterlibatan karyawan tersebut dalam pelaksanaan tugas pekerjaan. ${ }^{14}$ Menurut kamus besar bahasa Indonesia pengalaman diartikan sebagai yang pernah dialami (dijalani, dirasa, ditanggung). Pengalaman kerja menunjukkan berapa lama agar supaya karyawan bekerja dengan baik. Pengalaman kerja meliputi banyaknya jenis pekerjaan atau jabatan yang pernah diduduki oleh seseorang dan lamanya mereka bekerja pada masing-masing pekerjaan atau jabatan. ${ }^{15}$ Dengan adanya pengalaman kerja maka telah terjadi proses penambahan ilmu pengetahuan dan keterampilan serta sikap pada diri seseorang, sehingga dapat menunjang dalam pengembangan diri dengan perubahan yang ada. $^{16}$

Melalui suatu pendidikan, seseorang belajar bersosialisasi dengan sekelilingnya. 
Pendidikan juga merupakan suatu proses mendorong terwujudnya pemikiran-pemikiran dan tindakan kreatif yang menyebabkan terjadinya perubahan dan kemajuan budaya. Menurut Andrew E. Sikula dalam Mangkunegara, pendidikan adalah suatu proses jangka panjang yang menggunakan prosedur sistematis dan terorganisir, yang mana tenaga manajerial mempelajari pengetahuan konseptual dan teotitis untuk tujuan-tujuan umum. ${ }^{17}$ Menurut UndangUndang Sisdiknas 2003, indikator tingkat pendidikan terdiri atas jenjang pendidikan dan kesesuaian jurusan. ${ }^{18}$

Jenjang pendidikan adalah tahapan pendidikan yang ditetapkan berdasarkan tingkat perkembangan peserta didik, tujuan yang dicapai, dan kemampuan yang dikembangkan. Pendidikan tertinggi responden yaitu profesi Ners dan terendah D3 keperawatan. Sesuai dengan ketentuan Undang-Undang Keperawatan tahun 2014 terkait jenis perawat adalah vokasi dan profesi dengan minimal pendidikan D3 Keperawatan. $^{19}$

Sebagian besar kinerja perawat IGD dengan kategori baik yaitu $74 \%$ diikuti dengan gaya kepemimpinan demokratis kepala ruangan sebesar $35 \%$. Penelitian ini sejalan dengan hasil penelitian yang dilakukan Rochman, Ridwan dan Afifah dengan hasil kinerja perawat di RSUD C dengan kriteria baik sebesar 52,3\% pada tahun 2014. Kinerja pada dasarnya apa yang dilakukan karyawan atau yang tidak dilakukan karyawan. Kinerja karyawan adalah suatu hal yang memengaruhi seberapa banyak mereka memberi kontribusi kepada organisasi. Perbaikan kinerja baik untuk individu maupun kelompok menjadi pusat perhatian dalam upaya meningkatkan kinerja organisasi. ${ }^{20}$

Hasibuan mengatakan kinerja adalah hasil kerja nyata dan standar kualitas maupun kuantitas yang dihasilkan setiap karyawan. $^{21}$ As'ad menyimpulkan bahwa kinerja adalah hasil yang dicapai seseorang menurut ukuran yang berlaku pada pekerjaan yang bersangkutan. ${ }^{22}$ Perawat sebagai salah satu tenaga kesehatan di rumah sakit memegang peranan penting dalam upaya mencapai tujuan pembangunan kesehatan. Keberhasilan pelayanan kesehatan bergantung pada partisipasi perawat dalam memberikan asuhan keperawatan yang berkualitas bagi pasien. ${ }^{23}$

Profesi keperawatan menurut Potter and Perry merupakan profesi yang penting dalam bidang kesehatan, karena perawat mengetahui kondisi pasien selama 24 jam. Tugas perawat secara langsung bersentuhan kepada pasien yaitu memenuhi kebutuhan dasar berupa kebersihan diri, nutrisi, keamanan, kenyamanan, keseimbangan cairan, istirahat dan tidur, serta eliminasi (buang air besar dan kecil). Jam kerja perawat yang terbagi menjadi 3 sift per hari membuat perawat di rumah sakit lebih mengetahui kondisi pasien dibandingkan dengan tenaga kesehatan lainnya. Asuhan 
keperawatan yang diberikan pun lebih holistic (utuh) yang meliputi biologis, psikologis, social, dan spiritual pada pasien. ${ }^{23}$

Standar penilaian kinerja perawat menurut Nursalam adalah pernyataan deskriptif mengenai kualitas pelayanan yang diinginkan untuk menilai pelayanan keperawatan yang telah diberikan kepada pasien. Tujuan dari standar keperawatan adalah meningkatkan asuhan keperawatan, mengurangi biaya asuhan keperawatan, dan melindungi perawat dari kelalaian dalam melaksanakan tugas dan melindungi pasien dari tindakan yang tidak terapeutik. Dalam menilai kualitas pelayanan keperawatan kepada klien digunakan standar praktik keperawatan yang merupakan pedoman bagi perawat dalam melaksanakan asuhan keperawatan. ${ }^{24}$ Standar praktik keperawatan telah dijabarkan oleh PPNI (Persatuan Perawat Nasional Indonesia) yaitu pengkajian pasien, diagnosis keperawatan, perencanaan keperawatan, implementasi keperawatan, dan evaluasi keperawatan.

Seorang manajer keperawatan dituntut untuk dapat melakukan perencanaan keperawatan, pengorganisasian keperawatan, pengarahan, pengendalian, dan mengevaluasi sarana dan prasarana keperawatan yang tersedia untuk dapat memberikan asuhan keperawatan yang efektif dan efisien. $^{24}$ Kepala ruang atau manajer keperawatan akan langsung berhubungan dengan kegiatan pelayanan kesehatan pada klien. Gillies menjelaskan bahwa seorang perawat manajer adalah seorang penggerak bawahannya agar mau bekerja sesuai filosofi, visi, dan misi yang ada dalam organisasi, sehingga dapat meningkatkan kinerja perawat. ${ }^{25}$

Menurut Nursalam faktor-faktor yang memengaruhi kinerja adalah supervisi dan gaya kepemimpinan. ${ }^{2}$ Dari hasil penelitian ini gaya kepemimpinan keperawatan yang di gunakan kepala ruang keperawatan IGD di DIY sebagian besar dengan kinerja baik sebayak 35\% yaitu demokratis. Gaya kepemimpinan demokratis menurut Thoha yaitu gaya yang dikaitkan dengan kekuatan personal dan keikutsertaan para pengikut dalam proses pemecahan masalah dan pengambilan keputusan. ${ }^{26}$

Sutikno (2014) mengatakan pemimpin dengan gaya kepemimpinan demokratis selalu menerima dan menghargai saransaran, pendapat, dan nasihat dari staf dan bawahan, melalui forum musyawarah untuk mencapai kesepakatan. Kepemimpinan demokratis adalah kepemimpinan yang aktif dan dinamis serta terarah. Kegiatan pengendalian dilaksanakan secara tertib dan bertanggung jawab. Pembagian tugas disertai pelimpahan wewenang dan tanggung jawab yang jelas, memungkinkan setiap anggota berpartisipasi secara aktif. ${ }^{27}$ Sejalan dengan penelitian yang dilakukan di rumah sakit swasta di Demak oleh Maryanto, Pujiyanto, dan Setyono dengan hasil sebagian besar kepala ruang menerapkan gaya kepemimpinan demokratis. ${ }^{28}$ 


\section{KESIMPULAN}

Kinerja perawat IGD di RSUD A sebagian besar dalam kategori baik, kinerja perawat IGD di RSUD B sebagian besar dalam kategori cukup, kinerja perawat IGD di RSUD C sebagian besar dalam kategori baik, kinerja perawat IGD di RSUD D sebagian besar dalam kategori baik, dan kinerja perawat IGD di RSUD E sebagian besar dalam kategori baik. Gaya kepemimpinan demokratis kepala ruang perawat IGD di DIY mendapatkan hasil sebagian besar kinerja perawat dalam kategori baik.

\section{TERIMA KASIH}

1. Prof. H. Mohamad Nasir, Ph.D., Ak. Menteri Riset Teknologi dan Pendidikan Tinggi Repulik Indonesia, email: menristekdikti@ristek.go.id

2. Kuswanto Hardjo, dr., M.Kes. Ketua Stikes Jenderal Achmad Yani Yogyakarta, email: info@stikesayaniyk.ac.id

\section{KEPUSTAKAAN}

1. Nursalam. Manajemen Keperawatan: Aplikasi Dalam Praktik Keperawatan Profesional Edisi Ketiga. Jakarta: Salemba Medika. 2012

2. Nursalam. Manajemen Keperawatan Aplikasi Dalam Praktik Keperawatan Profesional. Jakarta : Salemba Medika. 2002

3. Schriver, J. A., Talmadgee, R., Chuong, R., Hedges, J.R. Emergency Nursing: Historical, 2003. Current and Future Roles. Journal of Emergency Nursing 29 (5): 431-439.

4. Kementrian Kesehatan RI. 2009. Standar Instalasi Gawat Darurat ( IGD ) Rumah Sakit. Nomor 856/Menkes/SK/IX/2009
5. Nurmawilis, N. Pengaruh Gaya Kepemimpinan dan Kepuasan Kerja TerhadapKinerja Karyawan Di RSUD Rokan Hulu Riau. 2008 Tesis. http://repository.usu.ac.id/bitstream/12345 6789/6684/1/09E00154.pdf.Diakses 29 April 2016

6. Anwar, Syaiful, dan Supardi. Dasar-dasar Perilaku Organisasi. Yogyakarta: UII Press Yogyakarta. 2002

7. Depkes RI. Standar Pelayanan Rumah Sakit. Cetakan kedua. Jakarta. 2004

8. Upton. P. Psikologi Perkembangan. Surabaya: Erlangga. 2012

9. Cahyadi dan Mubin. Psikologi Perkembangan. Ciputat: Quantum Teaching. Ciputat Press Group. 2006

10. Potter dan Perry. Fundamental Keperawatan Buku 1 Ed. 7. Jakarta: Salemba Medika. 2009

11. Pieter, H.Z. \& Lubis, N.L. Pengantar Psikologi Dalam Keperawatan.Jakarta: Kencana. 2010

12. Soedirman dan Suma"mur P.K., Kesehatan Kerja dalam Perspektif Hiperkes dan Keselamatan Kerja, Erlangga, Magelang. 2014

13. Nitisemito, Pengelolaan tentang Kondisi Kerja; Jakarta Erlangga. 2008

14. Manulang. Manajemen Personalia. Jakarta, Ghalia Indonesia. 1984

15. Hasibuan, Manajemen Sumber Daya Manusia, Bumi Aksara, Jakarta, 2000, hlm.109

16. Syafaruddin, Manajemen Sumber Daya Manusia Strategi Keunggulan Kompetitif, BPFE-Yogyakarta, 2008, hlm. 237.

17. Mangkunegara, Perencanaan dan Pengembangan Sumber Daya Manusia, Bandung: Refika aditama. 2003

18. Departemen Pendidikan Nasional, 2003. Undang-Undang Nomor 20 Tahun 2003, Tentang Sistem Pendidikan Nasional, Jakarta: Depdiknas.

19. Kementrian Kesehatan RI, 2014. UndangUndang Nomor 38 Tahun 2014, Tentang Praktik Keperawatan, Jakarta: Kemenkes.

20. Mathis dan Jackson, Human Resource Management. Alih Bahasa, Jakarta: Salemba empat. 2002: 78.

21. Hasibuan. Manajemen Sumber Daya Manusia, Edisi Revisi. Bumi Aksara, Jakarta. 2003 
22. As'ad, M. Psikologi Industri. Edisi 4. Cetakan Ke Sepuluh. Liberti Yogyakarta. 2008

23. Potter and Perry. Buku Ajar Fundamental Keperawatan Konsep, Proses, dan Praktik. Edisi 4 volume 1.EGC. Jakarta. 2005

24. Nursalam. Manajemen Keperawatan: Aplikasi dalam Praktik Keperawatan Profesional Edisi Kedua. Jakarta: Salemba Medika. 2007

25. Gillies, D.A. Manajemen Keperawatan: Suatu Pendekatan Sistem. Edisi kedua. Philadelphia: W. B. Saunders. 2000

26. Thoha, Perilaku Organisasi, Konsep Dasar dan Implikasinya. Jakarta: PT Grafindo Persada. 2013

27. Sutikno, sobry M. Pemimpin Dan Gaya Kepemimpinan, Edisi Pertama Lombok: Holistica. 2014

28. Maryanto, Pujiyanto, Setyono. Hubungan Gaya Kepemimpinan Kepala Ruang Dengan Kepuasan Kerja Perawat di Rumah Sakit Swasta di Demak. Jurnal Managemen Keperawatan 2013 . Volume 1, No. 2, November 2013; 146-153 